\title{
Preparation and Characterization of Nano Pigments by Wet Milling Technique and Their Applications in Printing Inks Industry
}

\author{
Sherif M. Elshamy, Mostafa M. H. Khalil" and Adel M. G. Hanafi \\ Departments of Chemistry, Faculty of Science, Ain Shams University, 11566 Cairo, Egypt
}

\section{A R T I C LE I N F O}

Article history:

Received 08 August 2017

Accepted 11 September 2017

Keywords:

Offset ink;

Pigment nanoparticles;

Dispersion;

Optical density;

Gloss;

Transparency;

Ink film thickness.

\begin{abstract}
A B S T R A C T
Traditional offset inks have a pigment particle size more than $5 \mu \mathrm{m}$ due to the aggregate formation during the dispersion process. Being pigments are the most expensive part in the printing ink formulation, so achieving the optimum benefits of the pigments are necessary and that require decreasing the pigment particle size to the minimum available level (nano size). In this research two colors process sheet-fed offset inks (yellow-magenta) with nano sized pigments were prepared via top - bottom technique by using Eiger Torrance mini motor mill (Horizontal dyno mill machine). The procedure consisted of dispersing the pigment with suitable grinding varnish and different ratios of dispersants \& different milling times to investigate the influence of these factors on the pigment dispersion quality. Transmission electron microscopy (TEM) was used as the characterization technique and ensures that pigments reached nano size (20-200) $\mathrm{nm}$. The dispersant ratio and grinding time are found to affect the size and morphology to achieve the pigment nanoparticles. Two colors process sheet-fed offset inks (yellow-magenta) with pigment nanoparticles were compared with the corresponding traditional inks in all physical properties like (viscosity - tack ...etc) and also printing properties like (optical density- gloss-transparency ...etc) by comparing lab prints based on (ISO 2834-1 and ISO 2846-1). The research ensures that there were significant increases in optical density, gloss, transparency. According to the significant increase in optical color density of nano inks compared with traditional inks, the nano inks could be printed with very low IFT (ink film thickness) compared with traditional inks and gave the same optical color density, the lower IFT in the printing process means many benefits such as better set off properties, lower drying time and better rub resistance.
\end{abstract}

\section{Introduction}

Offset printing is a commonly used technique in which the inked image is transferred (or "offset") from a plate to a rubber blanket and then to the substrate. The offset printing process employs a flat (planographic) image carrier on which the image to be printed obtains ink from ink rollers, while the non-printing area attracts a water-based film (called "fountain solution"), keeping the non-printing areas ink-free ${ }^{[1]}$. The manufacture of printing ink is a technologically advanced highly specialized and complex process. The basic formulation of ink involves the grinding of pigment in a vehicle to form the pigment dispersion then letting down the pigment dispersion with suitable resins to meet rheological and functional properties. The pigment in

\footnotetext{
* Corresponding author.

E-mail address: Khali162@yahoo.com
}

most printing inks is the most expensive part of the formulation, economics of pigment selection and proper dispersion are of vital importance ${ }^{[2]}$. The production of ink depends on basic physical processes involving complete wetting of the pigments and their even distribution in the surrounding vehicle. This complex process is called "Dispersion", and has to be clearly differentiated from mixing or stirring ${ }^{[3]}$. The manufacturing of nanoparticles can be classified into top-down and bottom-up methods. No matter what kind of methods is used to fabricate the nanoparticles, the nanoparticles will aggregate again because the effects of Coulomb electrostatic forces and van der Waal forces ${ }^{[4]}$. Many mechanical processing methods have been successfully developed for dispersing agglomerated particles in liquids, including agitator discs, colloid mills, high-pressure homogenizers, triple roller mills, ball mills, 
sand mills and beads mills ${ }^{[\mathbf{5 , 0}]}$. To achieve the optimum benefits of a pigment, it is necessary to obtain as full a reduction as possible to the primary particle size. The color strength of a pigment depends on its exposed surface area, and the smaller the particle the higher the surface area and thus stronger the color ${ }^{[7,8]}$. Increasing demands on quality printing inks regarding the optical characteristics such as gloss, transparency or color strength require the use of more effective dispersing techniques ${ }^{[2]}$ it was found that pigment nanoparticles could be produced via a wet stirred media mill with a polymeric media, which is a wet-mill employing beads, is practically suitable for producing particles having a nanometer size range and has a production scale ranging from gram to kilogram [9]. In this paper two color process pigments are prepared in nano size dispersed in offset ink and compared in their rheological properties with the corresponding traditional inks for studying the effects in the printing process, we found that although The nano ink is a new technology and opens up a new category of printing, but in the printing Egyptian market there are no benefits from a new nano ink technology due to the lack of studies, the research aim is to Study the characteristics of traditional inks compared with nano inks to explain the benefits in the printing industry.

\section{Materials and methods}

\section{Chemicals and materials}

Pigments: Yellow Pigment: (Trade name: Irgalite yellow LBIW), Chemical name: Diarylide yellow, Color index: 13, Surface area: $18 \mathrm{~m}^{2} / \mathrm{g}$ was purchased from Ciba-Switzerland, and Magenta Pigment (Trade name: Irgalite Magenta D 4200), chemical name: Lithol Rubine 4B, color index: $57: 1$, surface area: $57 \mathrm{~m}^{2} / \mathrm{g}$ was purchased from Basf -Germany.

Dispersing agent: (Trade name: Solsperse 16000) description: $100 \%$ active polymeric dispersant, Appearance: viscous brown liquid, purchased from Lubrizol- USA.

Petroleum Distillate: Distillation range $(250-295)^{\circ} \mathrm{C}$, Aniline point (80), viscosity@ $40^{\circ} \mathrm{C}$ (2.5-3 stokes), purchased from Panama petroleum limited - India.

Resins (Phenolic modified rosin ester):

- Setaprint 1600c - structured viscoelastic, melting point: $160^{\circ} \mathrm{C}$ (ring \& ball) - purchased from Hexion China.

- Setaprint $2330 \mathrm{c}$, melting point: $150^{\circ} \mathrm{C}$ (ring \& ball) purchased from Lawter - China.

- Gemcol 707 H.S- High M.Wt, Melting point: $170^{\circ} \mathrm{C}$ (ring \&ball) purchased from Gem Synthetics - India.

- Setaprint $2654 \mathrm{c}$, high structured, melting point: $165^{\circ} \mathrm{C}$ (ring \& ball) purchased from Lawter - China.

\section{Other:}

- Drier: 6\% Co and 6\% Mn mix drier in distillate, purchased from Delta specialist - Egypt.

- Antioxidant: Butylated Hydroxy Toluene (BHT) purchased from Yasho Industrial - India.

- Wax: Luwax AF 31- polyethylene wax - purchased from Degussa - Germany.

- Linseed and soya bean oils.

\section{Tools and Equipments}

Laboratory stirrer with speed controller unit (0-5000) rpm was used for preparation of the sample for grinding. mini motor mill (Horizontal dyno mill ) purchased from Eiger Torrance company-England, Figure 1. With variable speed (0-5000) rpm, Chamber volume: $100 \mathrm{ml}$, Digital timer display, cooling system to maintain temperature, full steel design used for milling. Ceramic beads made of zirconium oxide/yttrium stabilized, size (0.8-1) mm, bulk density: $3.66 \mathrm{~kg} / \mathrm{L}$ (Sigmound LindnerGermany). The working operations for the mini mill machine were tip speed $=4000 \mathrm{rpm}$ and mill base temperature fixed during milling at $60-70{ }^{0} \mathrm{C}$ according to each color.

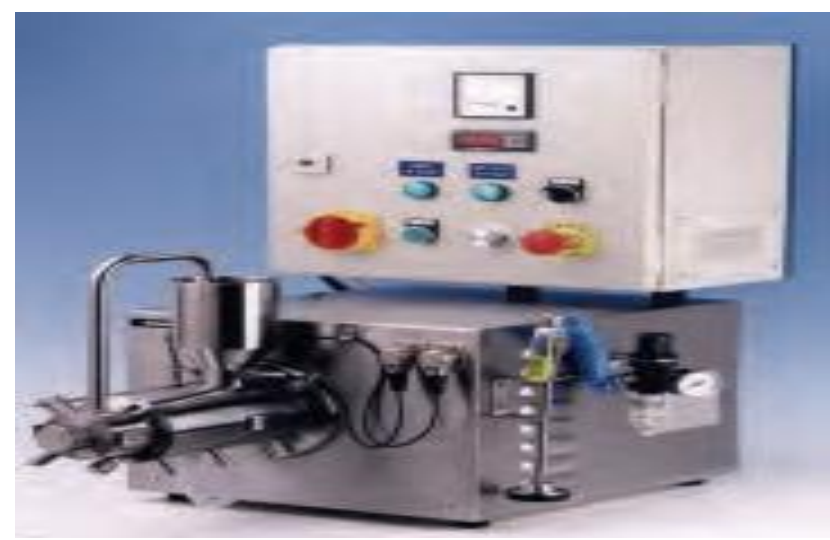

Fig. 1: Mini motor mill machine - Eiger Torrance company-England

A slight modification on the mini-mill machine was made because offset ink is quite viscous in nature (paste ink) so when recirculation the ink builds up in the recirculation pipe and cease to flow. So the mini-mill machine modification was replacing the recirculation pipe with a short length of flexible hose to avoid the two 90 degree in the recirculation pipe and that was very useful especially in (yellow) mill base Figure 2, also thermometer was added to control ink temperature during milling.

The mini mill Dyno mill grinding machine was examined using zirconium beads yttrium stabilized with different sizes (0.4-0.6) \& (0.6-0.8) \&(0.8-1) $\mathrm{mm}$ and practically the $(0.8-1) \mathrm{mm}$ was the best in operation and results. It is possible to adjust the filling volume of beads at a value usually comprised between 70 and $85 \%$ [10]. The filling volume of beads was fixed at $80 \%$ which was found to be the optimum value for the mini mill machine, with respect to the time required to reach the limit size.

\section{Measuring and testing}

1. Viscosity and yield value: Laray viscometer (France)

2. Tack: Electronic digital inkometer - USA

3. Grinding: Grinding Gauge (0-50) Microns

4. Ink Flow: glass plate Flow meter angle 60

5. Prints: IGT orange Proofer - USA

6. Spectrophotometer: Spectroeye -Xrite (USA)

7. Gloss: Pico gloss SO3 (Erichsen) 


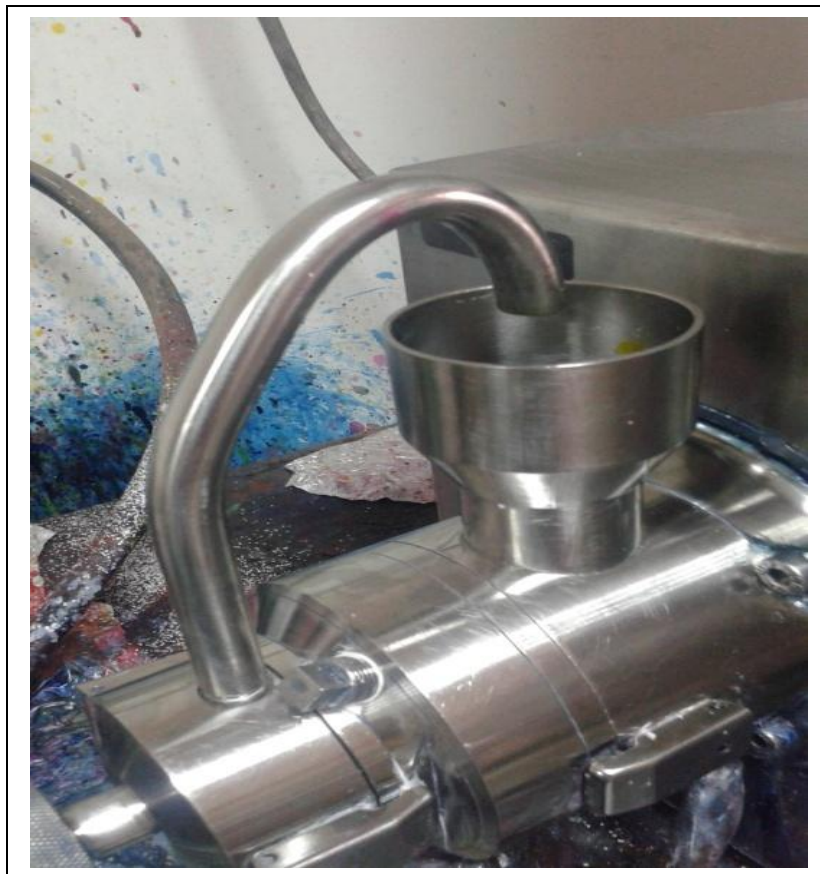

Dyno mill before modification

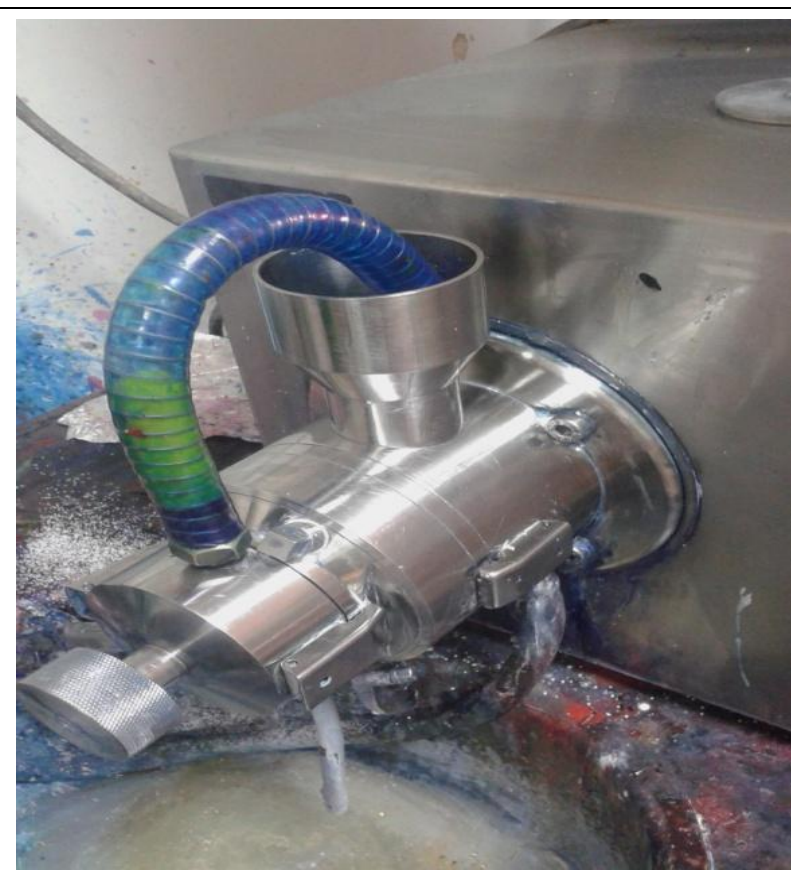

Dyno mill after modification

Fig. 2: Dyno mill (mini motor mill) before and after modification by flexible hose.

Table 1: The raw materials and their percentages in the grinding varnish.

\begin{tabular}{|l|l|}
\hline Raw materials & Percentage \% \\
\hline Soya bean oil & 14 \\
\hline Linseed oil & 34 \\
\hline Gemcol 707 H.S (phenolic resin ) & 25 \\
\hline Setaprint 2654c (phenolic resin) & 14 \\
\hline Butylated Hydroxy Toluene (BHT) & 0.3 \\
\hline Petroleum distillate & 12.7 \\
\hline Total & 100 \\
\hline
\end{tabular}

\section{Grinding Varnish}

Grinding varnish was prepared in order to use it as a part of the mill base which will be milled in the dyno mill machine.

Soya bean oil and linseed oil were heated to $200^{\circ} \mathrm{C}$ and the resins were added gradually in stages then hold temperature to $200^{\circ} \mathrm{C}$ for 60 minutes to ensure complete melting and then added the rest of the recipe at $130^{\circ} \mathrm{C}$ and stir well for 10 minutes then filtered on 10 microns filter. Evaluation of the varnish: viscosity $=130$ poise ${ }^{[11]}$, Yield value $=320$ dyne $\mathrm{cm}^{2[11]}$, tack $=13.5$ gram. Meter ${ }^{[12]}$.

\section{Grinding recipe for the pigments (mill base)}

In order to obtain nano sized yellow pigment (Diarylide yellow, Color index: 13) dispersed in the grinding media, grinding varnish was mixed with the dispersant and petroleum distillate (procedures illustrated in Table 2) and then stirred well under laboratory high speed stirrer at $3000 \mathrm{rpm}$ for 10 minutes and then pigment was added gradually in stages within 10 min under gently stirring and after complete addition, the grinding recipe was stirred under high speed at $5000 \mathrm{rpm}$ for $10 \mathrm{~min}$. The grinding recipes were taken and put in the mini mill (Dyno mill) machine using flexible hose instead of 90 degree pipe for better flow under tip speed $4000 \mathrm{rpm}$ and controlled temperature $\left(60^{\circ} \mathrm{C}\right.$ for yellow pigment) and different grinding times. A similar method for grinding was used for Magenta (Lithol Rubine 4B, color index: $57: 1$ ) but at controlled temperature $70^{\circ} \mathrm{C}$ (procedures illustrated in Table 3).

\section{Results and discussion}

\section{Grinding recipes (mill-base)}

General Idea

Many factors affecting the dispersion process illustrated as the following: the dispersing agent anchor group could attach firmly on the pigment surface. But the molecules of the resins in grinding varnish are transiently adsorbed on the pigment surface and even though not firmly anchored. So they hinder the dispersant anchoring process on the pigment surface so minimum resin solids should be used in the mill base. Also an opposite factor that if the percentage of dispersants is too much it will cause layer collapse and limited performance in the 
dispersion process. Also the low resin content and the effect of the dispersant in lowering the inter-particulate attraction will reduce dramatically the mill base viscosity to an extent that could be insufficient shear in the mill base to facilitate effective dispersion. ${ }^{[13]}$, also the recirculation in the dyno mill machine needs suitable mill base rheology and good flow. In order to solve all these issues, series of recipes were created including different percentages of pigments \& grinding varnish \& dispersing agent for each color to balance all these factors.

\section{For yellow color}

Many milling procedures were prepared to study the effect of dispersant ratio and grinding time in order to prepare nano sized yellow pigment dispersed in the grinding recipe, also the grinding recipe for yellow traditional ink was prepared, Table 2 . The color strength increases with decreasing particle size because of the larger surface area per unit mass and better bonds among the particles ${ }^{[14]}$. So we can use tinting strength test for the mill base as a function of pigment particle size reduction during the milling process. Tinting strength ${ }^{[16]}$ for the mill base were done by adding ( 0.1 gram mill base +4.9 gram white base) and make draw down print and after 24 hours five different places on the print measured using specrtoeye photometer instrument to measure the optical density under the following measuring conditions (physical filter :polarized, white base :Abs, illuminant :D50,observer angle: 2, density standard :DIN).

The dispersion was measured by Grinding gauge ${ }^{[17]}$ for the grinding recipe before grinding in the dyno mill and it exceed $50 \mu \mathrm{m}$.

From Table 2, it can be seen that the best dispersant ratio is $10 \%$ of the pigment content and increase the dispersant ratio above that there is no increase in the color strength. Also, procedures Y104 to Y 107 proved that as the grinding time increase there is no effect on the tinting strength so still $10 \%$ dispersant is the best. Furthermore, using the $10 \%$ dispersant proved that the optimum time for dispersion was 14 minutes (procedures
Y 108 to Y 111) and milling over that time has no effect on the dispersion.

The TEM Photos (Fig. 3) proved that the sample of Procedure Y 102 reach nano sized (25-40 nm) and for traditional grinding recipe there are large pigment agglomerates with sizes around $5 \mu \mathrm{m}$ and were much smaller than the size obtained using the grinding gauge ${ }^{[17]}$ which was around $10 \mu \mathrm{m}$.

\section{For magenta color}

Many milling procedures were prepared to study the effect of dispersant ratio and grinding time in order to prepare nano sized magenta pigment dispersed in the grinding recipe, also the grinding recipe for magenta traditional ink was prepared, Table 3. The color strength increases with decreasing particle size because of the larger surface area per unit mass and better bonds among the particles ${ }^{[14]}$. So we can use tinting strength test for the mill base as a function of pigment particle size reduction during the milling process. Tinting strength ${ }^{[16]}$ for the mill base were done by adding ( 0.1 gram mill base +4.9 gram white base) and make draw down print and after 24 hours five different places on the print measured using specrtoeye photometer instrument to measure the optical density under the following measuring conditions (physical filter :polarized, white base: Abs, illuminant: D50,observer angle: 2, density standard: DIN).

The dispersion was measured by Grinding gauge ${ }^{[17]}$ for the grinding recipe before grinding in the dyno mill and it exceed $50 \mu \mathrm{m}$.

From Table 3, it can be seen that the best dispersant ratio is $25 \%$ of the pigment content and increase the dispersant ratio above that there is no increase in the color strength. Also, procedures M104 to M107 proved that as the grinding time increase there is no effect on the tinting strength so still $25 \%$ dispersant is the best. Furthermore, using the $25 \%$ dispersant proved that the optimum time for dispersion was 20 minutes (procedures M 108 to M 111) and milling over that time has no effect on the dispersion.

Table 2: List of milling procedures for yellow color including grinding times and color strength measurements.

\begin{tabular}{|c|c|c|c|c|c|c|c|}
\hline \multirow{2}{*}{ Procedure } & \multirow{2}{*}{ Pigment \% } & \multicolumn{2}{|c|}{ Dispersant } & Petroleum & Grinding & Grinding & $\begin{array}{c}\text { Color strength } \\
\text { obtained by tinting } \\
\text { Strength test }\end{array}$ \\
\cline { 3 - 7 } & & In mill base & $\begin{array}{c}\text { Ratio \% according } \\
\text { to pigment content }\end{array}$ & & & Distillate \\
\hline Y 100 & 20 & - & $(0 \%)$ & 25 & 55 & 14 & 0.50 \\
\hline Y 101 & 20 & 1 & $(5 \%)$ & 25 & 54 & 14 & 0.50 \\
\hline Y 102 & $\mathbf{2 0}$ & $\mathbf{2}$ & $\mathbf{( 1 0 \% )}$ & $\mathbf{2 5}$ & $\mathbf{5 3}$ & $\mathbf{1 4}$ & $\mathbf{0 . 5 3}$ \\
\hline Y 103 & 20 & 3 & $(15 \%)$ & 25 & 52 & 14 & 0.52 \\
\hline Y 104 & 20 & - & $(0 \%)$ & 25 & 55 & 22 & 0.50 \\
\hline Y 105 & 20 & 1 & $(5 \%)$ & 25 & 54 & 22 & 0.51 \\
\hline Y 106 & 20 & 2 & $(10 \%)$ & 25 & 53 & 22 & 0.53 \\
\hline Y 107 & 20 & 3 & $(15 \%)$ & 25 & 52 & 22 & 0.52 \\
\hline Y 108 & 20 & 2 & $(10 \%)$ & 25 & 53 & 10 & 0.52 \\
\hline Y 109 & 20 & 2 & $(10 \%)$ & 25 & 53 & 12 & 0.52 \\
\hline Y 110 & 20 & 2 & $(10 \%)$ & 25 & 53 & 16 & 0.53 \\
\hline Y 111 & 20 & 2 & $(10 \%)$ & 25 & 53 & 18 & 0.53 \\
\hline $\begin{array}{c}\text { Traditional } \\
\text { grinding recipe }\end{array}$ & $\mathbf{2 0}$ & $\mathbf{1}$ & $\mathbf{5 \%}$ & $\mathbf{2 5}$ & $\mathbf{5 4}$ & $\mathbf{4}$ & $\mathbf{0 . 4 8}$ \\
\hline
\end{tabular}




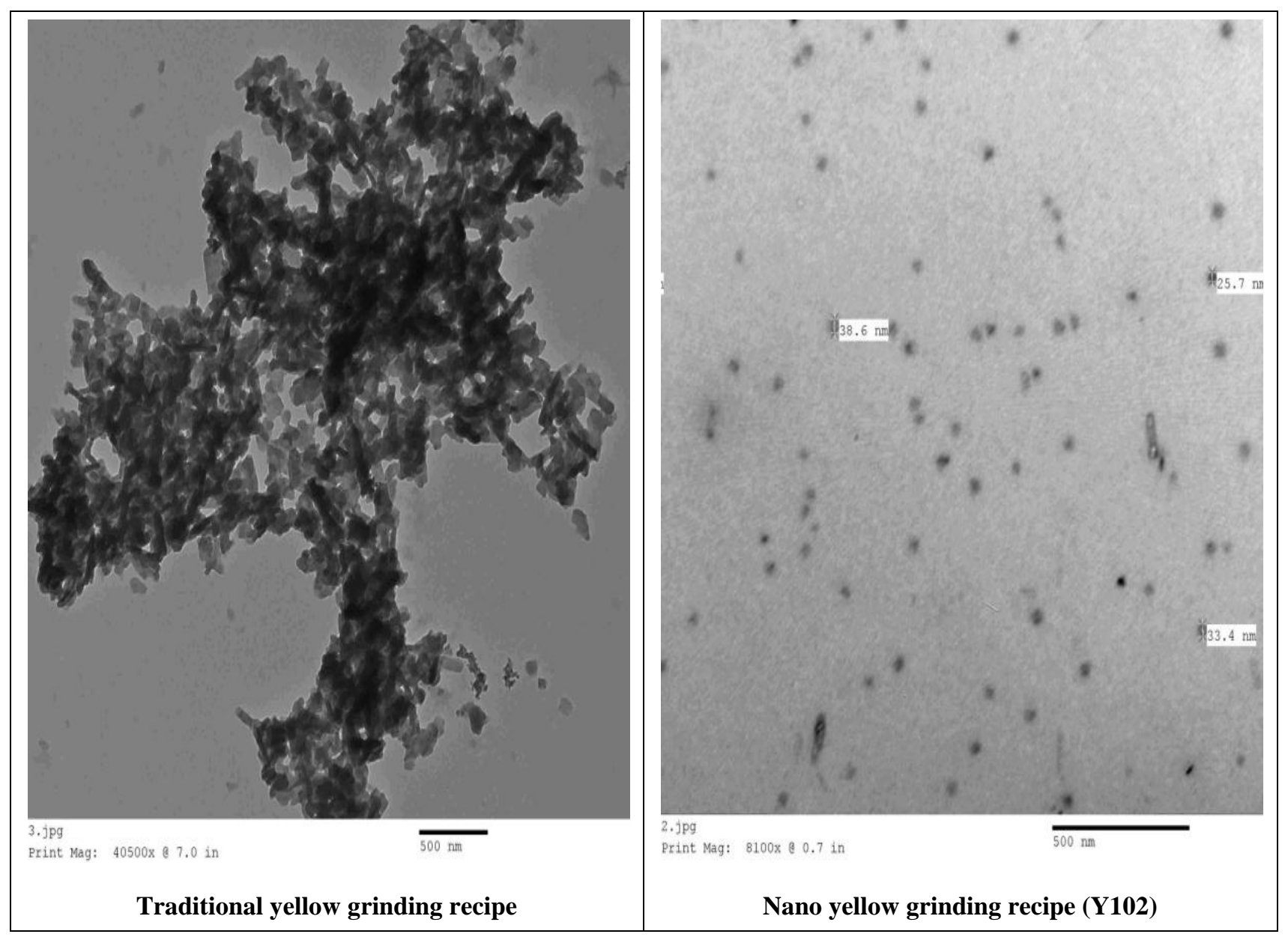

Fig. 3: TEM photos for traditional and nano sized yellow grinding recipes.

Table 3: List of milling procedures for magenta pigment including grinding times and color strength measurements.

\begin{tabular}{|c|c|c|c|c|c|c|c|}
\hline \multirow[b]{2}{*}{ Procedure } & \multirow[b]{2}{*}{ Pigment \% } & \multicolumn{2}{|c|}{ Dispersant } & \multirow{2}{*}{$\begin{array}{c}\text { Petroleum } \\
\text { Distillate }\end{array}$} & \multirow{2}{*}{$\begin{array}{l}\text { Grinding } \\
\text { Varnish }\end{array}$} & \multirow{2}{*}{$\begin{array}{l}\text { Grinding } \\
\text { time (min) }\end{array}$} & \multirow{2}{*}{$\begin{array}{l}\text { Color strength } \\
\text { obtained by tinting } \\
\text { strength test }\end{array}$} \\
\hline & & In mill base & $\begin{array}{l}\text { Ratio \% according } \\
\text { to pigment content }\end{array}$ & & & & \\
\hline M 100 & 25 & - & $0 \%$ & 21 & 54.50 & 20 & 0.55 \\
\hline M 101 & 25 & 5 & $20 \%$ & 19 & 51 & 20 & 0.56 \\
\hline M 102 & 25 & 6.25 & $25 \%$ & 18.75 & 50 & 20 & 0.57 \\
\hline M 103 & 25 & 7.50 & $30 \%$ & 18 & 49.50 & 20 & 0.56 \\
\hline M 104 & 25 & - & $0 \%$ & 21 & 54.50 & 26 & 0.57 \\
\hline M 105 & 25 & 5 & $20 \%$ & 19 & 51 & 26 & 0.57 \\
\hline M 106 & 25 & 6.25 & $25 \%$ & 18.75 & 50 & 26 & 0.57 \\
\hline M 107 & 25 & 7.50 & $30 \%$ & 18 & 49.50 & 26 & 0.57 \\
\hline M 108 & 25 & 6.25 & $25 \%$ & 18.75 & 50 & 16 & 0.55 \\
\hline M 109 & 25 & 6.25 & $25 \%$ & 18.75 & 50 & 18 & 0.56 \\
\hline M 110 & 25 & 6.25 & $25 \%$ & 18.75 & 50 & 22 & 0.57 \\
\hline M 111 & 25 & 6.25 & $25 \%$ & 18.75 & 50 & 24 & 0.57 \\
\hline $\begin{array}{c}\text { Traditional } \\
\text { grinding recipe }\end{array}$ & 25 & 3.50 & $14 \%$ & 19.50 & 52 & 5 & 0.50 \\
\hline
\end{tabular}

The TEM Photos (Fig. 4) proved that the sample of procedure M 102 reach nano size of $20-40 \mathrm{~nm}$ and it is rod-like shape with length of $100-250 \mathrm{~nm}$ and not particles as yellow pigment and for traditional grinding recipe there are large agglomerates with sizes around 5 $\mu \mathrm{m}$ which was much smaller than the size obtained using the grinding gauge ${ }^{[17]}$ which was around $10 \mu \mathrm{m}$. 


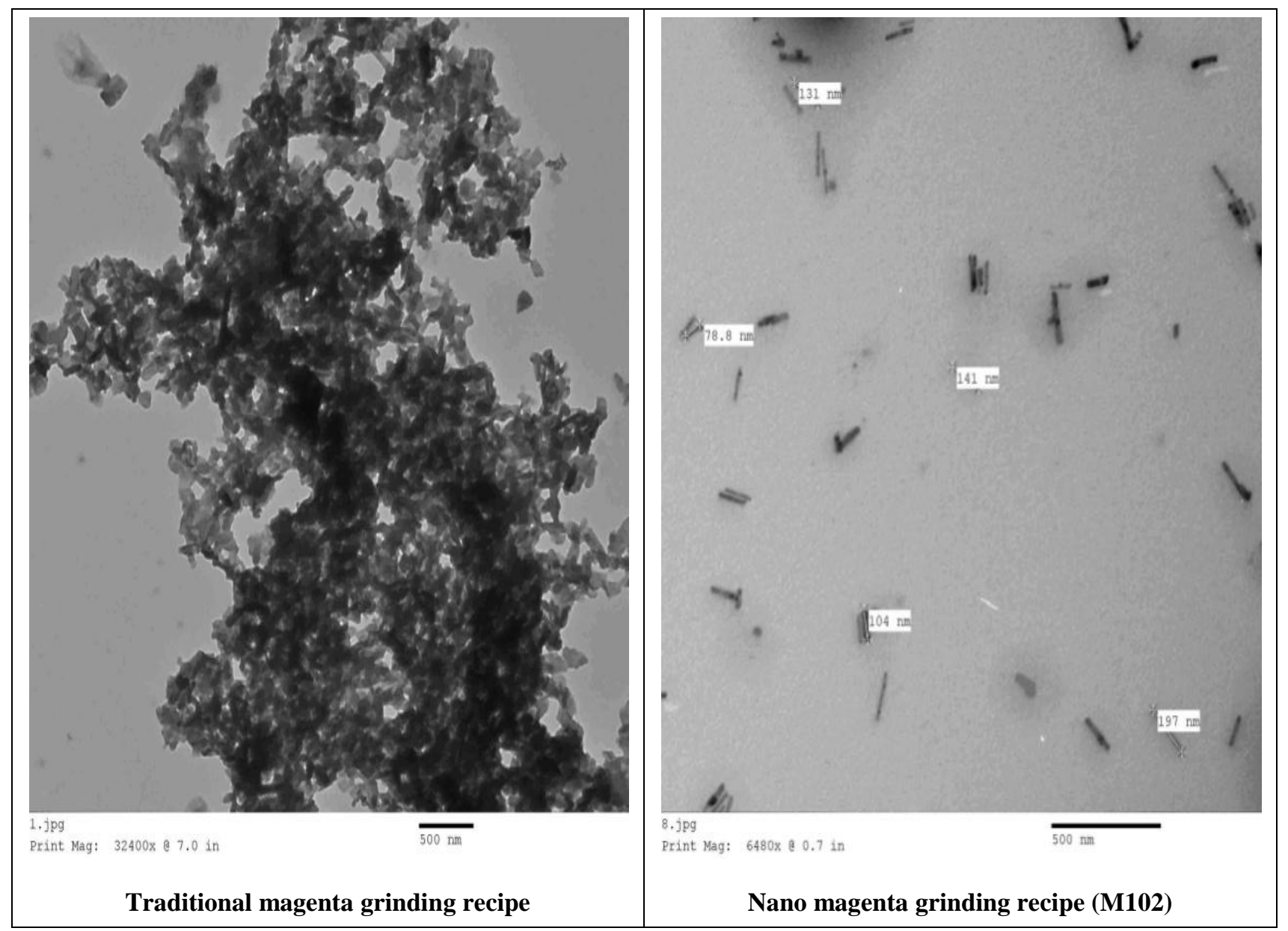

Fig. 4: TEM photos for traditional and nano sized magnta grinding recipes.

\section{Preparing of the Nano and traditional offset printing inks \\ 1- Let down varnish}

Let down varnish was prepared in order to be used as a part of the final printing ink recipe (Table 4).

Soya bean oil was heated to $200^{\circ} \mathrm{C}$ and the resins were added gradually in stages then hold temperature to $200^{\circ} \mathrm{C}$ for 60 minutes to ensure complete melting and then added the rest of the recipe at $130^{\circ} \mathrm{C}$ and then raise temperature to $170^{\circ} \mathrm{C}$ for 10 minutes to enable gelling agent to take action then filtered on 10 microns filter. The obtained varnish properties: viscosity $=380$ poise
${ }^{[11]}$, Yield value $=6320$ dyne $\mathrm{cm}^{2}{ }^{[11]}$, tack $=11$ gram. Meter ${ }^{[12]}$. 2- Preparing Nano \& traditional offset ink (yellow and magenta) (Table 5)

All ingredients were mixed except drier and stirred well on laboratory stirrer at $5000 \mathrm{rpm}$ for 5 minutes and then drier added and all recipe stirred for 5 minutes.

More petroleum distillates were added to the nano offset recipes to make it closer in rheology to traditional offset recipes for better evaluation in printing tests and that is because of Nano-milling increase the number of particles per unit area so the total surface area was increased and that will increase viscosity and tack (Table 6).

Table 4: The raw materials and their percentages in the let down varnish.

\begin{tabular}{|l|l|}
\hline Raw materials & Percentage \% \\
\hline Soya bean oil & 18 \\
\hline Setaprint 1600c (phenolic resin) & 22 \\
\hline Setaprint 2330c (phenolic resin) & 22 \\
\hline Butylated Hydroxy Toluene (BHT) & 0.5 \\
\hline Petroleum distillate & 36 \\
\hline Gelling agent (50\%in distillate) & 1.5 \\
\hline total & $\mathbf{1 0 0}$ \\
\hline
\end{tabular}


Table 5: Final preparation of traditional \&nano inks for yellow and magenta inks.

\begin{tabular}{|l|c|c|c|c|}
\hline \multirow{2}{*}{ color } & \multicolumn{2}{|c|}{ Yellow } & \multicolumn{2}{c|}{ Magenta } \\
\cline { 2 - 5 } & traditional & Nano & traditional & Nano \\
\hline Grinding recipe (\%) & 60 & 60 & 60 & 60 \\
\hline Let down varnish (\%) & 35 & 34 & 35 & 32 \\
\hline $\begin{array}{l}\text { Antioxidant (BHT) } \\
\mathbf{2 0 \%} \text { in petroleum distillate }\end{array}$ & 1 & 1 & 1 & 1 \\
\hline $\begin{array}{l}\text { Wax (20\% polyethylene in grinding } \\
\text { varnish }\end{array}$ & 3 & 3 & 3 & 3 \\
\hline Drier (6\% Co\& 6\% Mn) in distillate & 1 & 1 & 1 & 1 \\
\hline Petroleum distillate & - & 1 & - & 3 \\
\hline Total & $\mathbf{1 0 0}$ & $\mathbf{1 0 0}$ & $\mathbf{1 0 0}$ & $\mathbf{1 0 0}$ \\
\hline
\end{tabular}

Table 6: Rheology comparison between two colors process traditional inks and Nano inks.

\begin{tabular}{|c|c|c|c|c|}
\hline \multirow{2}{*}{ ingredients } & \multicolumn{2}{|c|}{ Yellow } & \multicolumn{2}{|c|}{ Magenta } \\
\hline & traditional & Nano & traditional & Nano \\
\hline Grinding TEM & $\approx 5 \mu$ & $(25-40) \mathrm{nm}$ & $\approx 5 \mu$ & $(20-40) \mathrm{nm}$ \\
\hline Viscosity at $25^{\circ} \mathrm{C}^{[10]}$ & 125 & 133 & 141 & 150 \\
\hline Yield value at $25^{\circ} \mathrm{C}^{[10]}$ & 946 & 956 & 1635 & 1817 \\
\hline Tack at $32^{\circ} \mathrm{C}^{[11]}$ & 8 & 8.5 & 9.8 & 10.6 \\
\hline Flow, angle 60 at $25^{\circ} \mathrm{C}$ for $10 \mathrm{~min}$ & 6.5 & 8 & 9 & 11 \\
\hline
\end{tabular}

Comparison of the printing properties of the two colors process nano offset inks(yellow\&magenta) and corresponding two colors process traditional inks

Using IGT orange proofer instrument, prints for each color were taken at different Ink films thickness based on (ISO 2834-1) ${ }^{[18]}$ on a gloss white coated paper (120 $\left.\mathrm{gram} / \mathrm{m}^{2}\right)$ to measure optical density and gloss and transparency and opacity (ISO 2846-1) ${ }^{[19]}$ and also CIE lab and $\Delta \mathrm{E}$ were measured noting that we didn't use the standard paper for ISO 2846-1 (150 g/m2- APCO II / IImade by papierfabrik scheufelen) as it ceased of production from may $2013^{[20]}$ and that has no effect on the printing results because similarity of two inks on a reference substrate generally ensures similarity on another substrate ${ }^{[19]}$.

For Ink Film Thickness (IFT) calculation ${ }^{[19]}$

$S=\Delta M / \rho \times A$

(Eq. 1)

Where:-

$\Delta M$ is the difference in mass of the disk before and after printing;

$\rho$ is the mass density of the ink

$A$ is the printed area.

For $\Delta \mathrm{E}$ calculation ${ }^{[21]}$

$$
\Delta \mathrm{Eab}=\sqrt{\left(\mathrm{L}_{2}-\mathrm{L}_{1}\right)^{2}+\left(\mathrm{a}_{2}-a_{1}\right)^{2}+\left(b_{2}-b_{1}\right)^{2}}
$$

Figure 5, illustrate the CIE color lab

L: lightness from (0-100), zero is black and 100 is white

a: moves from red to green

b: moves from yellow to cyan

$\Delta$ Eab: the color difference between two colors ( $\mathrm{a} \& \mathrm{~b}$ )

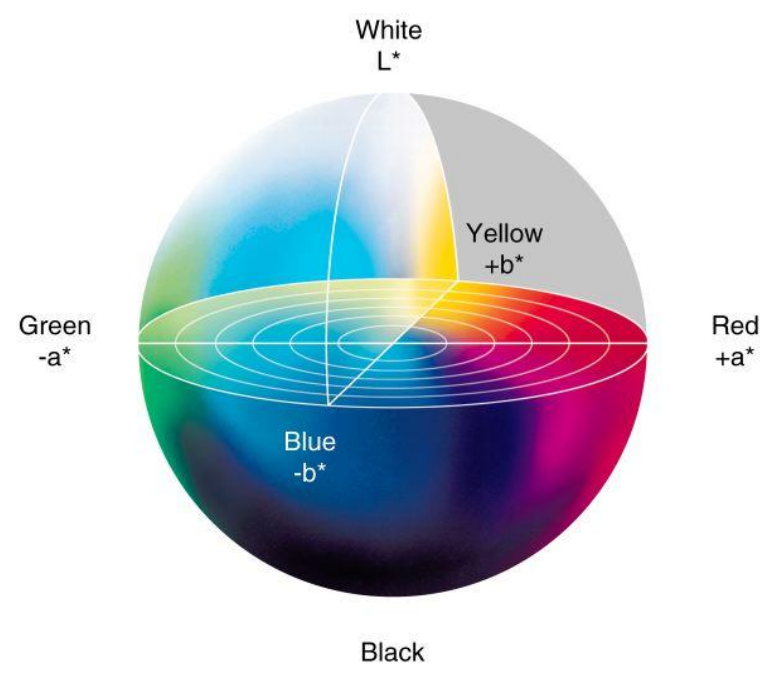

Fig. 5: The CIE color lab

For transparency calculation ${ }^{[19]}$

$T=(S 1-S 2) /(\Delta E a b 1-\Delta E a b 2)$

Where

$T$ : is the value of the transparency measurement;

$S 1$ : is the ink film for the point on the graph at the higher level of film thickness;

$S 2$ : is the ink film for the point on the graph at the lower level of film thickness;

$\triangle E a b 1$ : is the color difference for the point on the graph at the higher level;

$\triangle E a b 2$ : is the color difference for the point on the graph at the lower level. 
Table 7 and Figures 6 and 7 illustrate that the optical density and gloss of nano yellow ink are much more than traditional yellow ink. As if we assume that we need to make a print with an optical density of 1.80 so using the traditional ink we need to print with $\mathrm{IFT}=1.55$ and if we use the nano ink we need to print with IFT= 1.15 meaning that the color strength of the nano yellow ink is more than traditional ink by $26 \%$. Also the gloss will be 64 for traditional ink and 72 for nano yellow ink which means the gloss of nano ink is better than traditional ink by $11 \%$.

Table 7: Comparison of optical Density and gloss and CIE 1,a,b, $\Delta \mathrm{E}$ at different ink film thickness (IFT) between Nano offset ink and Traditional Ink. (Yellow color).

\begin{tabular}{|c|c|c|c|c|c|c|c|c|c|c|c|}
\hline Type & \multicolumn{4}{|c|}{ Traditional yellow color process offset Ink } & \multicolumn{5}{c|}{ Nano yellow color process offset Ink } \\
\hline $\begin{array}{c}\text { IFT } \\
\boldsymbol{\mu m}\end{array}$ & $\begin{array}{c}\text { Optical } \\
\text { Density }\end{array}$ & Gloss & $\mathbf{L}$ & $\mathbf{a}$ & $\mathbf{b}$ & $\begin{array}{c}\text { IFT } \\
\boldsymbol{\mu m}\end{array}$ & $\begin{array}{c}\text { Optical } \\
\text { Density }\end{array}$ & Gloss & $\mathbf{L}$ & $\mathbf{a}$ & $\mathbf{b}$ \\
\hline $\mathbf{0 . 8 0}$ & 1.37 & 60 & 92.61 & -7.12 & 99.47 & $\mathbf{0 . 8 0}$ & 1.49 & 69.30 & 92.75 & -7.21 & 103.38 \\
\hline $\mathbf{0 . 9 0}$ & 1.43 & 60.2 & 92.52 & -7.00 & 101.63 & $\mathbf{0 . 9 0}$ & 1.71 & 72.20 & 92.18 & -6.40 & 109.06 \\
\hline $\mathbf{1 . 2 0}$ & 1.53 & 59.30 & 92.29 & -6.40 & 105.11 & $\mathbf{1 . 2 0}$ & 1.84 & 72 & 91.98 & -5.70 & 112.49 \\
\hline $\mathbf{1 . 3 0}$ & 1.75 & 64.80 & 91.83 & -5.62 & 110.92 & $\mathbf{1 . 3 0}$ & 1.88 & 74.1 & 91.89 & -5.65 & 113.14 \\
\hline $\mathbf{1 . 9 0}$ & 1.99 & 66.40 & 91.27 & -3.80 & 116.87 & $\mathbf{1 . 4 0}$ & 2.01 & 75 & 91.58 & -4.79 & 116.06 \\
\hline
\end{tabular}

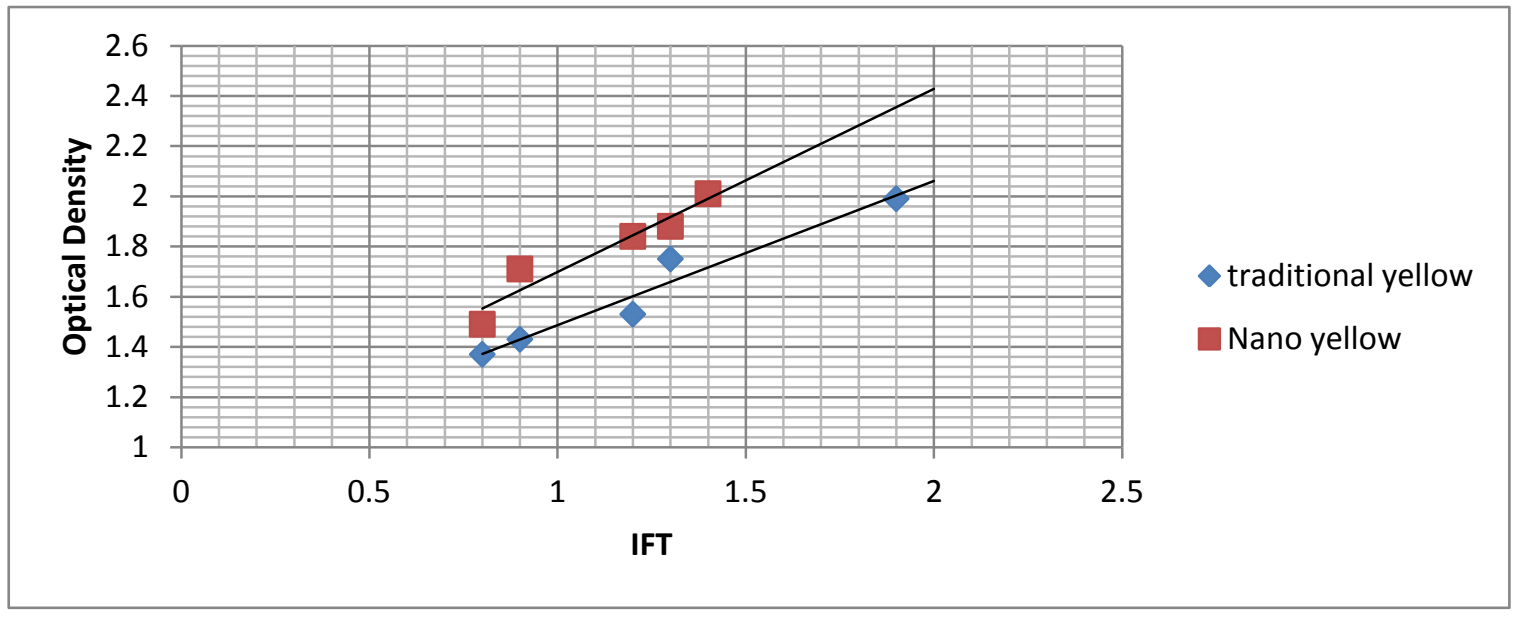

Fig. 6: optical density comparison

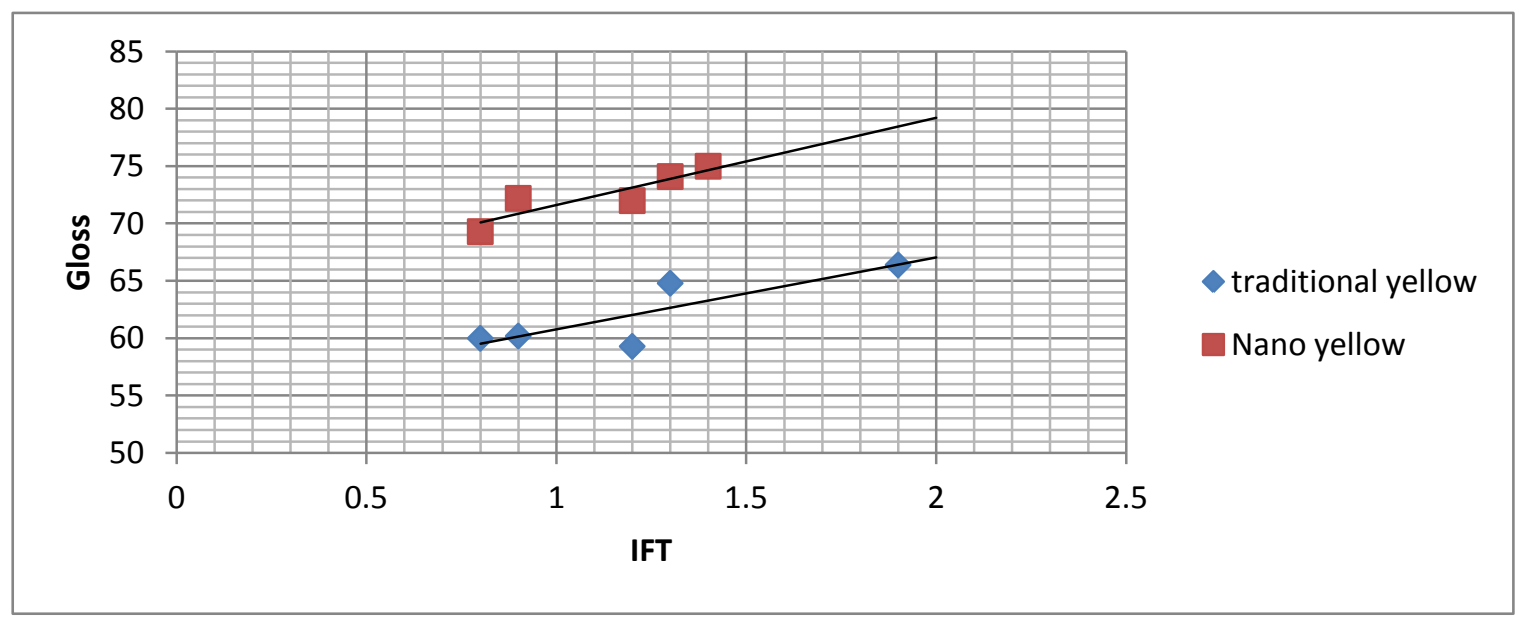

Fig. 7: optical density comparison 
Black print strips were cut and $(1, a, b)$ were measured using spectroeye photometer and then yellow prints with different (IFT) were applied over the black print strips and $(1, a, b)$ were measured again and $\Delta \mathrm{E}$ were calculated according to Eq.2 to measure the differences between black strips before and after printing yellow ink and all data illustrated in Table $8^{[19]}$.
Transparency calculation according to Eq. $3^{[19]}$

Traditional yellow ink $=1.9-0.8 / 7.19-3.35=0.29$

Nano yellow ink $=1.40-0.80 / 2.48-2.83=-1.71$

The minus value of transparency of nano yellow ink means that the ink is super transparent ${ }^{[19]}$.

Figure $\mathbf{8}$ illustrate that transparency of nano yellow ink is much more than traditional yellow ink

Table 8: Comparison of Transparency between Nano offset ink and Traditional Ink (yellow color).

\begin{tabular}{|c|c|c|c|c|c|c|c|c|c|c|c|c|c|c|c|}
\hline Type & \multicolumn{7}{|c|}{ Traditional yellow color process offset Ink } & \multicolumn{8}{|c|}{ Nano yellow color process offset Ink } \\
\hline \multirow{2}{*}{$\begin{array}{l}\text { IFT } \\
\mu \mathrm{m}\end{array}$} & \multicolumn{3}{|c|}{$\begin{array}{l}\text { Black prints before } \\
\text { printing yellow color }\end{array}$} & \multicolumn{3}{|c|}{$\begin{array}{l}\text { Black prints after } \\
\text { printing yellow color }\end{array}$} & \multirow[t]{2}{*}{$\Delta \mathbf{E}$} & \multirow{2}{*}{$\begin{array}{l}\text { IFT } \\
\mu \mathrm{m}\end{array}$} & \multicolumn{3}{|c|}{$\begin{array}{l}\text { Black prints before } \\
\text { printing yellow color }\end{array}$} & \multicolumn{3}{|c|}{$\begin{array}{l}\text { Black prints after } \\
\text { printing yellow color }\end{array}$} & \multirow[t]{2}{*}{$\Delta \mathbf{E}$} \\
\hline & $\mathbf{L}$ & $\mathbf{a}$ & b & $\mathbf{L}$ & $\mathbf{a}$ & b & & & $\mathbf{L}$ & $\mathbf{a}$ & b & $\mathbf{L}$ & $\mathbf{a}$ & b & \\
\hline 0.80 & 1.55 & -0.14 & 0.56 & 3.03 & -2.40 & -1.42 & 3.35 & 0.80 & 1.32 & -0.10 & 0.45 & 2.67 & -1.83 & -1.33 & 2.83 \\
\hline 0.90 & 1.54 & -0.16 & 0.53 & 2.94 & -2.59 & -1.36 & 3.38 & 0.90 & 1.85 & -0.22 & 0.61 & 3.61 & -2.02 & -0.48 & 2.74 \\
\hline 1.20 & 1.71 & -0.08 & 0.61 & 3.47 & -3.24 & -0.59 & 3.81 & 1.20 & 1.80 & -0.21 & 0.42 & 3.34 & -2.22 & -0.70 & 2.61 \\
\hline 1.30 & 1.55 & -0.10 & 0.47 & 4.06 & -4.67 & -0.12 & 5.25 & 1.30 & 1.70 & -0.11 & 0.25 & 2.65 & -2.46 & -0.29 & 2.59 \\
\hline 1.90 & 1.42 & -0.15 & 0.46 & 4.84 & -6.46 & 0.87 & 7.19 & 1.40 & 1.64 & -0.04 & 0.32 & 2.61 & -1.52 & -1.42 & 2.48 \\
\hline
\end{tabular}

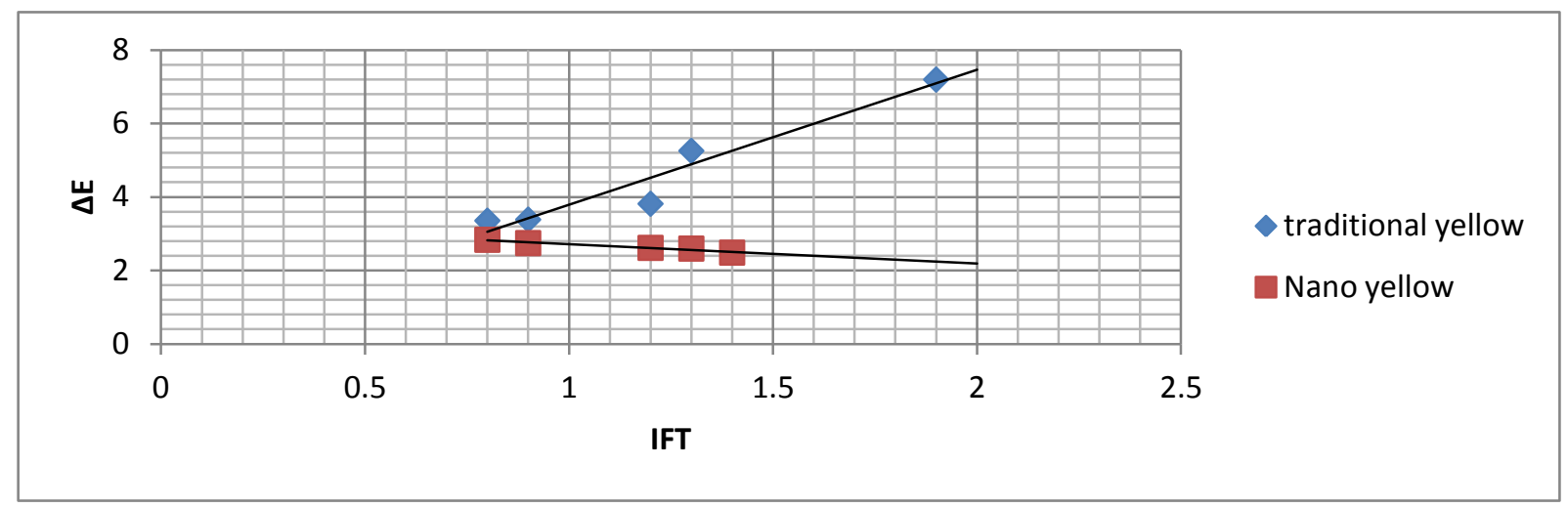

Fig. 8: Comparison of transparency of nano yellow and traditional yellow ink.

Table 9 and Figures 9 and 10 illustrate that the optical density and gloss of nano magenta ink are much more than traditional magenta ink.. As if we assume that we need to make a print with an optical density of 2.00 so using the traditional ink we need to print with $\mathrm{IFT}=1.60$ and if we use the nano ink we need to print with $\mathrm{IFT}=1.40$ meaning that the color strength of the nano magenta ink is more than traditional ink by $12.5 \%$. Also the gloss will be 63 for traditional ink and 76 for nano magenta ink which means the gloss of nano ink is better than traditional ink by $17 \%$.

Table 9: Comparison of optical Density \& gloss \& CIE 1,a,b , $\Delta \mathrm{E}$ at different ink film thickness between Nano offset ink \& Traditional Ink .(Magenta color).

\begin{tabular}{|c|c|c|c|c|c|c|c|c|c|c|c|}
\hline Type & \multicolumn{3}{|c|}{ Traditional Magenta color process offset Ink } & \multicolumn{6}{c|}{ Nano Magenta color process offset Ink } \\
\hline $\begin{array}{c}\text { IFT } \\
\boldsymbol{\mu m}\end{array}$ & $\begin{array}{c}\text { Optical } \\
\text { Density }\end{array}$ & Gloss & $\mathbf{L}$ & $\mathbf{a}$ & $\mathbf{b}$ & $\begin{array}{c}\text { IFT } \\
\boldsymbol{\mu m}\end{array}$ & $\begin{array}{c}\text { Optical } \\
\text { Density }\end{array}$ & $\mathbf{G l o s s}$ & $\mathbf{L}$ & $\mathbf{a}$ & $\mathbf{b}$ \\
\hline $\mathbf{1 . 2 0}$ & 1.64 & 45.60 & 47.18 & 80.78 & 0.03 & $\mathbf{1 . 1 0}$ & 1.76 & 69.20 & 47.32 & 82.81 & 0.74 \\
\hline $\mathbf{1 . 3 0}$ & 1.81 & 48.50 & 45.77 & 81.80 & 4.20 & $\mathbf{1 . 3 0}$ & 1.90 & 72.60 & 46.33 & 83.27 & 4.09 \\
\hline $\mathbf{1 . 6 0}$ & 2.02 & 50.80 & $44 . .62$ & 82.60 & 8.45 & $\mathbf{1 . 5 0}$ & 2.18 & 73.60 & 44.66 & 83.48 & 10.69 \\
\hline $\mathbf{1 . 7 0}$ & 2.07 & 52.60 & 44.30 & 82.55 & 10.09 & $\mathbf{1 . 7 0}$ & 2.26 & 75 & 44.03 & 83.15 & 12.94 \\
\hline $\mathbf{2 . 0 0}$ & 2.30 & 54.80 & 42.82 & 82.30 & 17.39 & $\mathbf{1 . 8 0}$ & 2.37 & 76.60 & 43.46 & 83.09 & 16.45 \\
\hline
\end{tabular}




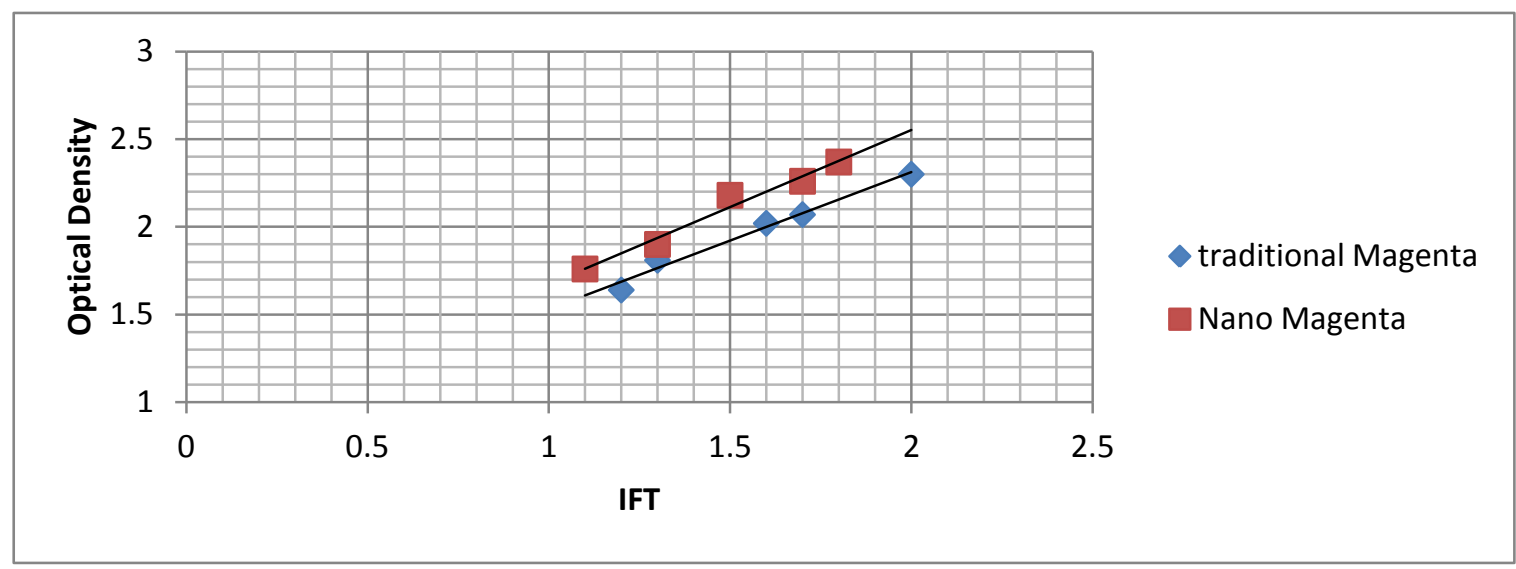

Fig. 9: Optical density comparison.

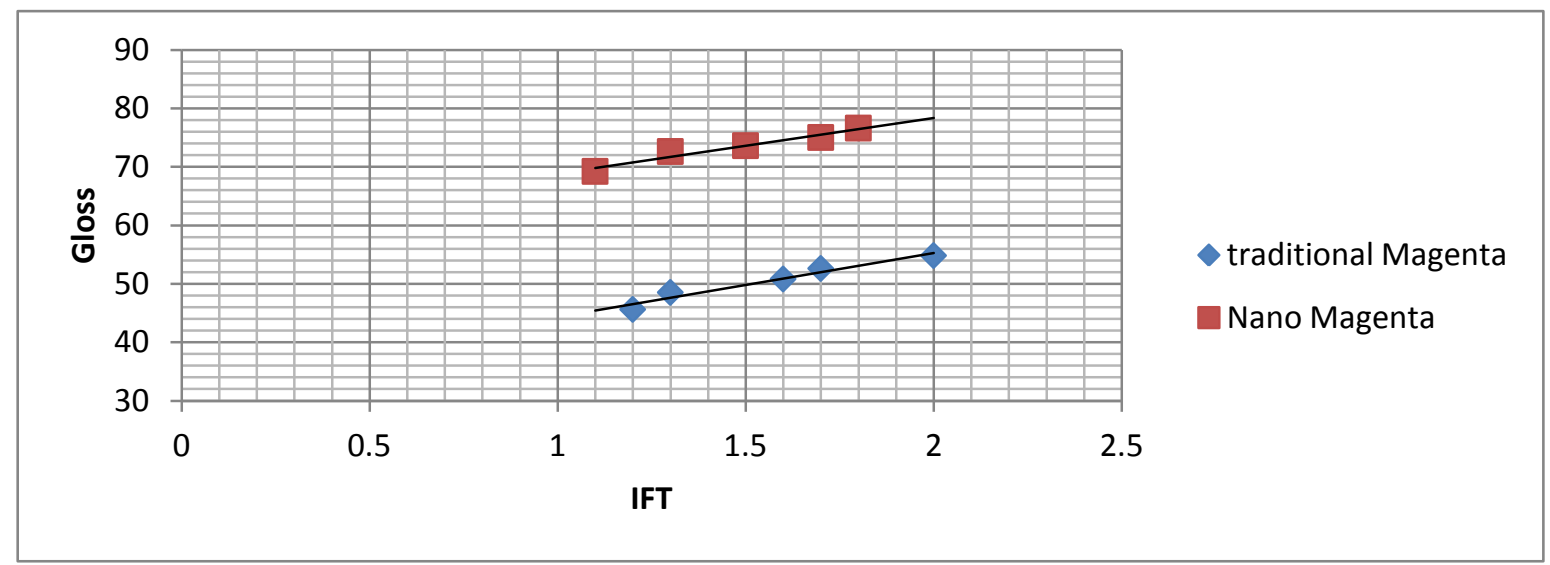

Fig. 10: Gloss comparison.

Black print strips were cut and $(1, a, b)$ were measured using spectroeye photometer and then magenta prints with different (IFT) were applied over the black print strips and $(1, a, b)$ were measured again and $\Delta \mathrm{E}$ were calculated according to Eq.2 to measure the differences between black strips before and after printing magenta ink and all data illustrated in Table $10^{[19]}$

Transparency calculation according to Eq. $3^{[19]}$, give the value of 0.19 for traditional magenta ink and 0.39 for the nano magenta ink. That approved nano magenta ink is more transparent than the traditional magenta ink (Fig. 11).

Table 10: Comparison of Transparency between Nano offset ink and Traditional Ink. (Magenta color).

\begin{tabular}{|c|c|c|c|c|c|c|c|c|c|c|c|c|c|c|c|}
\hline Type & \multicolumn{7}{|c|}{ Traditional magenta color process offset Ink } & \multicolumn{8}{|c|}{ Nano magenta color process offset Ink } \\
\hline \multirow[t]{2}{*}{$\begin{array}{c}\text { IFT } \\
\boldsymbol{\mu m}\end{array}$} & \multicolumn{3}{|c|}{$\begin{array}{c}\text { Black prints before } \\
\text { printing magenta } \\
\text { color } \\
\end{array}$} & \multicolumn{3}{|c|}{$\begin{array}{c}\text { Black prints after } \\
\text { printing magenta } \\
\text { color }\end{array}$} & \multirow[t]{2}{*}{$\Delta \mathbf{E}$} & \multirow[t]{2}{*}{$\begin{array}{l}\text { IFT } \\
\mu \mathrm{m}\end{array}$} & \multicolumn{3}{|c|}{$\begin{array}{c}\text { Black prints before } \\
\text { printing magenta } \\
\text { color } \\
\end{array}$} & \multicolumn{3}{|c|}{$\begin{array}{l}\text { Black prints after } \\
\text { printing magenta } \\
\text { color } \\
\end{array}$} & \multirow[t]{2}{*}{$\Delta \mathbf{E}$} \\
\hline & $\mathbf{L}$ & $\mathbf{a}$ & $\mathbf{b}$ & $\mathbf{L}$ & $\mathbf{a}$ & $\mathbf{b}$ & & & $\mathbf{L}$ & $\mathbf{a}$ & b & $\mathbf{L}$ & $\mathbf{a}$ & b & \\
\hline 1.20 & 1.00 & -0.06 & 0.01 & 3.29 & 4.19 & 3.43 & 5.92 & 1.10 & 0.65 & -0.12 & -0.19 & 2.44 & 2.83 & 2.39 & 4.31 \\
\hline 1.30 & 1.00 & -0.10 & -0.02 & 3.41 & 5.00 & 3.54 & 6.67 & 1.30 & 0.75 & 0.03 & -0.18 & 2.49 & 3.33 & 2.55 & 4.62 \\
\hline 1.60 & 1.05 & -0.03 & -0.03 & 3.72 & 6.18 & 4.20 & 7.97 & 1.50 & 0.83 & -0.04 & -0.11 & 2.76 & 4.20 & 2.74 & 5.46 \\
\hline 1.70 & 0.99 & -0.04 & -0.10 & 3.73 & 6.48 & 4.13 & 8.24 & 1.70 & 0.75 & -0.10 & 0.02 & 2.80 & 4.51 & 2.87 & 5.80 \\
\hline 2.00 & 0.94 & 0.06 & -0.19 & 4.13 & 8.14 & 4.89 & 10.06 & 1.80 & 1.04 & 0.06 & 0.04 & 2.94 & 5.01 & 3.08 & 6.11 \\
\hline
\end{tabular}




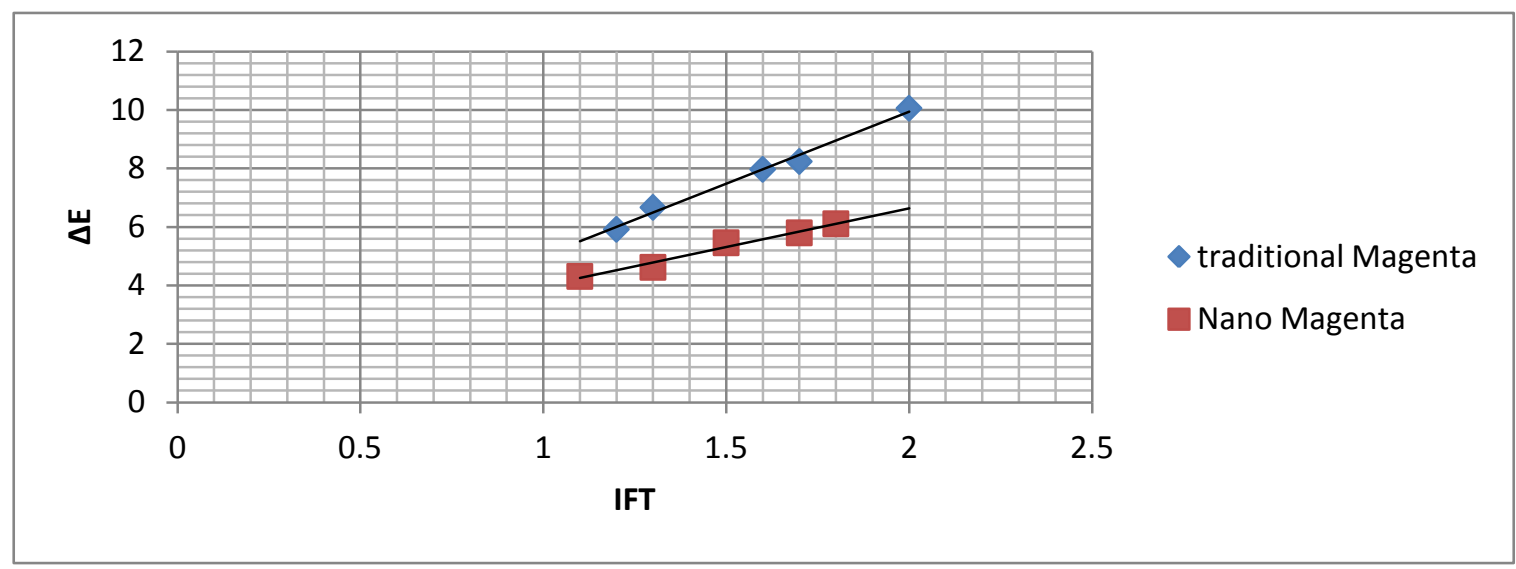

Fig. 11: Comparison of transparency of nano magenta and traditional magenta ink.

\section{Conclusion}

1- Two colors process nano offset ink were successfully prepared using Dyno mill machine with zirconium beads yttrium stabilized $(0.8-1) \mathrm{mm}$ with slight modification in the machine by replacing the steel recirculation pipe $\left(90^{\circ}\right)$ by short flexible hose and that gave better flow rates especially in yellow ink.

2- The evaluation of nano inks proved that there is an increase in viscosity and tack but with better flow compared with traditional inks and that would be due to the effect of increasing pigment surface area of pigment and well dispersion in the nano sized ink.

3- Nano inks gave superior printing properties compared with traditional inks especially in optical color density and gloss and transparency confirmed by lab prints.

4- The nano inks could be printed with very low IFT compared with traditional inks and give the same optical color density, the lower IFT in the printing process means many benefits in printing process in the press as better set off properties, lower drying time, better rub resistance, more durability of zinc plate, lower dot gain, lower misting, scumming problems and allow printing at higher speed machines so lowering printing costs. Also superior gloss helps to print without using gloss over print varnishes.

\section{References}

1) Comparative analysis of solid ink density, print contrast and Print gloss of metalized board printed with sheet fed offset printing process and dry toner based digital ink process, International journal of engineering sciences \& research technology, Aman Bhardwaj, Vandana, ISSN: 2277-9655, DOI: 10.5281/zenodo.57051, July, 2016.

2) Parfitt, G. D. (1973). Dispersion of Powders in Liquids, with Special Reference to Pigments London, Applied Science Publishers.

3) Sharma, M. K. and Micale, F. J. (1991). Surface Phenomena and Fine Particles in Water-based Coating and Printing Technology, New York: Plenum Press.

4) Yokoyama, T. and Hung, C. C. (2005). Nanoparticle technology for the production of functional materials. KONA, 23:7-16.

5) Muller, F., Peukert, W., Polke, R. and Stenger, F. (2004). Dispersing nanoparticles in liquids. Int. J. Miner. Process., 74:31-41.

6) Mckay, R. B. (1994). Technological Applications of Dispersion, Dekker: New York, USA.

7) Thompson, B. (1998). Printing Materials: Science and Technology, PIRA, p. 329-330.

8) Frimova, A., Pekarovicova, A., Fleming, P. D. and Pekarovic, A. (2005). "Ink Stability During Printing",TAGA J., 2.

9) Tanaka, Y., Inkyo, M., Yumoto, R., Nagai, J., Takano, M. and Nagata, S. (2009). Nanoparticulation of poorly water soluble drugs using a wet-mill process and physicochemical properties of the nanopowders, Chem. Pharm. Bull. 57:1050-1057.

10) kwade, A. (1999). wet comminution in stirred millsresearch and its practical application. Powder technol., 105:14-20).

11) ASTM D4040-05. Standard Test Method for Rheological Properties of Paste Printing and Vehicles by the Falling-Rod Viscometer. ASTM International 2005.<http://www.astm.org>.

12) ASTM D4361-97. Standard Test Method for Apparent Tack of Printing Inks and Vehicles by a Three-Roller Tack meter. ASTM International 1997. $<$ http://www.astm.org >.

13) Hyperdispersant Technology and Benefits-Lubrizol) available download at Website: www.solsperse.com, July 2008.

14) Ferguson L. D. (1992). Introduction to Printing Technology and Ink Chemistry, Deinking Seminar, Atlanta, GA, USA, 10:22-24.

15) Thompson B. (1998). Printing Materials, Science and Technology, Pira International,Ed.1, Surrey, p567.

16) ASTM D2066-07 (2012). Standard Test Methods for Relative Tinting Strength of Paste-Type Printing Ink Dispersions. ASTM International 2012. <http://www.astm.org >. 
17) ASTM D 1316 - 93 (Reapproved 2001. Standard Test Method for Fineness of Grind of Printing Inks By the NPIRI Grindometer. ASTM International 1993. <http://www.astm.org>.

18) ISO 2834-1:2006 Graphic technology - Laboratory preparation test prints-Part 1: Paste inks.(2006).

19) ISO 2846-1:2006. Graphic technology-Colour and transparency of ink sets for four-colour printing-
Part 1: Sheet-fed and heat-set web off set lithographic printing (2006).

20) Ink formation -Huber group company - germany, $1^{\text {st }}$ edition may 2013, Rev. 1, available at http://www.hubergroup.net/pdf-files/inkformarion/ INKFORMATION 4 en 02.pdf

21) Offset Print Analysis with Mathematical Regression Model (2016), 1Nandakumar M., 2Bose N., Acta Graphica 27(2):15-20. 